\title{
Nueva época de oro para el cine mexicano: una mirada local en el horizonte mundial del mercado cinematográfico
}

\section{Lucila Hinojosa Córdova ${ }^{1}$}

Recibido: 27/05/2018

Aprobado por pares: 27/09/2018
Enviado a pares: $31 / 05 / 2018$

Aceptado: 19/10/2018

DOI: $10.5294 /$ pacla.2019.22.3.5

Para citar este artículo / to reference this article / para citar este artigo Hinojosa, L. (2019). Nueva época de oro para el cine mexicano: una mirada local en el horizonte mundial del mercado cinematográfico. Palabra Clave, 22(3), e2235.

DOI: http://doi.org/10.5294/pacla.2019.22.3.5

\section{Resumen}

Este trabajo tiene como propósito destacar la recuperación que ha tenido el cine mexicano del tercer milenio, en el contexto de las condiciones de producción, exhibición y asistencia a las salas de cine comercial que en el periodo de 2010 a 2017 han prevalecido en el país, luego de recuperarse de una etapa de gran crisis que en la década de los noventa casi lo hizo desaparecer. El estudio forma parte de una línea de investigación que sobre la economía política del cine mexicano se ha venido realizando mediante la aplicación de una metodología mixta, en que se combinan la investigación documental, el análisis de contenido, la encuesta y la entrevista. Los resultados que aquí se muestran señalan que a partir de 2000 la industria cinematográfica mexicana empezó a recuperar sus indicadores de producción, asistencia y recaudación en taquilla; no obstante, esta recuperación no se ve en la exhibición de películas nacionales en las salas de cine comercial, que

1 orcid.org/0000-0003-0541-5347. Universidad Autónoma de Nuevo León, México. lucila.hinojosacr@uanl.edu.mx 
está condicionada por una legislación inequitativa para el sector que se modificó para integrarse a las demandas del capitalismo global. Los resultados también se comparan con los indicadores de otros países iberoamericanos y se complementan con datos empíricos obtenidos de estudios locales sobre los públicos que asisten a las salas de cine comercial de una importante ciudad del noreste de México. Con este estudio, se busca aportar conocimiento al campo de las industrias culturales en América Latina.

\section{Palabras clave (Fuente: tesauro de la Unesco)}

Cine; Cine mexicano; industria cinematográfica; producción audiovisual; exhibición; públicos; usuario cultural; audiencias. 


\section{The New Golden Age of Mexican Cinema: A Local View of the Global Horizon of the Film Market}

\section{Abstract}

This paper aims to highlight the recovery of third millennium Mexican cinema in relation to the conditions of production, exhibition and attendance at commercial movie theaters that have prevailed in the country between 2010-2017, after a serious crisis that almost made it disappear in the 1990s. The study is part of a line of research into the political economy of Mexican cinema that has been conducted using a mixed method, combining documentary research, content analysis, surveys, and interviews. Results suggest that, since 2000, the Mexican film industry has been improving its production, attendance and box office indicators. Still, this is not reflected in the exhibition of national films at commercial movie theaters, which is conditioned by inequitable legislation for the sector that was amended to meet the demands of global capitalism. Results are also compared with indicators of other Ibero-American countries and supplemented by empirical data obtained from local studies about the audiences attending commercial movie theaters of an important city in northeastern Mexico. This study seeks to contribute knowledge to the field of cultural industries in Latin America.

\section{Keywords (Source: Unesco Thesaurus)}

Film; Mexican cinema; film industry; film making; exhibitions; public; cultural users; audiences. 


\section{Nova época de ouro para o cinema mexicano: um olhar local no horizonte mundial do mercado cinematográfico}

\section{Resumo}

Este trabalho tem como objetivo destacar a recuperação que o cinema mexicano do terceiro milênio vem tendo no contexto das condições de produção, exibição e audiência que, entre 2010 e 2017, prevaleceram no país, após se recuperar de uma grande crise que, na década de 1990, quase fez com que desaparecesse. Este estudo faz parte de uma linha de pesquisa sobre a economia política do cinema mexicano mediante a aplicação de uma metodologia mista, que abrange pesquisa documental, análise de conteúdo, questionário e entrevista. Os resultados demonstram que, a partir de 2000, a indústria cinematográfica mexicana começou a recuperar seus indicadores de produção e bilheteria; contudo, essa recuperação não se vê na exibição de filmes nacionais nas salas comerciais, que estão condicionadas por uma legislação desigual para o setor que se modificou para integrar-se às demandas do capitalismo global. Os resultados também são comparados com os indicadores de outros países ibero-americanos e complementados com dados empíricos de estudos locais sobre os públicos que vão às salas de cinema comercial de uma importante cidade do nordeste do México. Com este estudo, pretende-se contribuir para o campo das indústrias culturais na América Latina.

\section{Palavras-chave (Fonte: tesauro da Unesco)}

Cinema; cinema mexicano; indústria cinematográfica; produção audiovisual; display; público; usuário cultural; audiências. 


\section{Introducción}

La historia reciente de la industria del cine mexicano tiene un antes y un después de la firma del Tratado de Libre Comercio de América del Norte (TLCAN), el cual se firmó en 1992 y ahora se encuentra en renegociaciones con los Estados Unidos y Canadá. Esto trajo consigo un gran cambio social e histórico para nuestro cine.

Aun cuando en 1990 ya se empezaba a observar un declive en la producción con respecto a los años anteriores, ese año todavía se produjeron 75 películas, de las cuales se estrenaron 74 en los cines; en ese entonces, México contaba con 1896 salas de cine comercial, es decir, el 28,6 \% de la cantidad con las que de 2017 registra $(6,633)$, pero a las que todavía asistieron 197 millones de espectadores, cuando la población era entonces de 80,08 millones de habitantes, de acuerdo con las estadísticas del Instituto Nacional de Geografía y Estadística (Inegi), lo que promediaba 2,4 de asistencia/habitante y el precio del boleto en taquilla era regulado como parte de la canasta básica.

Pero la situación cambió a causa de la firma del TLCAN y de los cambios a la legislación de cine. La firma del TLCAN significó para México la entrada al proceso globalizador, con la adopción oficial de las políticas económicas neoliberales que desde la década de los ochenta imponía el capitalismo global, la apertura de los mercados, las privatizaciones y la desregulación de algunos sectores productivos y de servicios del país. Lo cierto es que México se integró al proceso globalizador sin prepararse para una competencia que por mucho era asimétrica en igualdad de condiciones para algunos sectores productivos, como lo fue para el sector de la industria cinematográfica mexicana.

En ese entonces, la legislación de cine vigente hasta 1992 establecía que las películas nacionales podían ser exhibidas hasta en un $50 \%$ del total de pantallas a nivel nacional. Si bien no siempre se obtenía una producción que aprovechara esta cuota de pantalla, al menos existía esta regulación como medida proteccionista para el sector. Hoy, las reformas a la legislación cinematográfica, resultado de los cambios regulatorios para negociar 
este sector en el TLCAN, establecen que a partir de 1997 se podrán exhibir películas nacionales hasta en un $10 \%$ de nuestras pantallas, con lo que los estrenos de películas extranjeras, por no decir estadounidenses, han venido a ocupar un lugar preponderante, no solo en las salas de cine comercial, sino también en el consumo audiovisual del espectador en otras plataformas como la televisión abierta, de paga e internet.

Esta apertura del mercado, los cambios regulatorios y las privatizaciones del sector trajeron consigo una gran crisis del cine mexicano en la década de los noventa, de forma que en 1997 se produjeron solo nueve películas, crisis de la cual se comenzó a recuperar a partir de 2000, primero con altas y bajas, luego ya con un crecimiento sostenido desde 2006.

En 1997, ante la crisis de la industria, el Gobierno federal implementó dos estímulos para la producción: el Fondo para la Producción Cinematográfica de Calidad (Foprocine) y el Fondo de Inversión y Estímulos al Cine (Fidecine), que aún y cuando la comunidad cinematográfica se dividió con algunos a favor y otros en contra, desde entonces han funcionado apoyando la producción.

Otra medida importante para la recaudación fue la aprobación del artículo 189 de la Ley del Impuesto Sobre la Renta (ISR), con la que se creó Estímulo Fiscal a Proyectos de Inversión en la Producción y Distribución Cinematográfica Nacional (Eficine), que permite acreditar el $10 \%$ del pago anual del ISR a los contribuyentes que inviertan en la producción cinematográfica, lo que ha permitido obtener recursos extraordinarios hasta por MXN 500 millones anuales. Esta medida ha permitido impulsar la producción de películas mexicanas a corto y mediano plazo, así como su distribución, aunque limitada, ya que luego los cineastas se topan con los exhibidores controlados en su mayoría por las distribuidoras transnacionales que privilegian la exhibición de sus propias películas en las salas de cine.

A pesar de estas dificultades, a la vuelta de dos décadas (1997-2017), se ha visto una notable recuperación del cine nacional con un significativo incremento en la producción, en el número de salas de cine, en la asisten- 
cia y en la recaudación en taquilla, una franca transformación con respecto a la década de mayor crisis en la historia reciente del cine mexicano, la de los noventa. Sin embargo, la asistencia del público a ver películas nacionales todavía no alcanza los índices que tenía antes de la entrada del TLCAN, ya que, con todo y que ahora somos más y la industria ha mejorado, todavía no alcanzamos esos niveles de proporción equilibrada entre la producción, la exhibición y la asistencia a las salas de cine a ver películas nacionales que se tenían antes del TLCAN. Sin embargo, nuestro cine se recupera y con ello sus públicos. En realidad, la vuelta del público a ver su cine es uno de los factores de mayor impacto en esta recuperación.

A partir de nuevos modelos de negocio y de buscar temáticas más cercanas a la vida cotidiana de los espectadores, nuevas generaciones de cineastas y productores han estado trabajando más con voluntad e iniciativa propia que con grandes presupuestos en la realización de sus películas para recuperar a su público, el cual ha tenido una gran participación en esta nueva etapa que para algunos es una nueva época del cine mexicano en el siglo XXI.

\section{Metodología}

Este artículo forma parte de una línea de investigación que se ha venido desarrollando desde 1998, con el propósito de analizar el impacto que las medidas que se adoptaron con motivo del TLCAN han tenido en el circuito cinematográfico de la producción, la exhibición y el consumo en las salas de cine comercial, de la cual se han publicado varios trabajos. Es un estudio descriptivo, longitudinal, en el que se han venido aplicando técnicas de investigación como la revisión documental, cuantitativas como el análisis de contenido y la encuesta y cualitativas como la entrevista.

En la revisión documental, se analiza la información publicada en los informes oficiales del Instituto Mexicano de Cinematografía (Imcine), informes internacionales, documentos y artículos científicos, reportajes y entrevistas publicados en la prensa para contrastar los datos con los empíricos obtenidos a nivel local y, con ello, obtener una perspectiva global/local del fenómeno de estudio. 
El análisis de contenido se aplica a las carteleras cinematográficas publicadas en la prensa local para observar el origen y la cantidad de películas por país que se exhiben en las salas de cine comercial, lo cual se ha publicado en otros artículos, no en el que nos ocupa. La encuesta se utiliza para conocer las opiniones y preferencias de los públicos que asisten a las salas de cine. Y la entrevista se realiza a especialistas y cineastas para profundizar en las variables de estudio, también publicado en otros trabajos.

En este artículo, solo se presenta un análisis actualizado de la información estadística consultada, enfocada, particularmente, en mostrar el lugar que ocupa actualmente el cine mexicano en el contexto iberoamericano en lo referente a producción y exhibición, y el rol que los públicos de cine están teniendo en esta nueva etapa para el cine nacional, mediante los resultados de los estudios empíricos locales realizados a los espectadores que acostumbran asistir a las salas de cine comercial distribuidas en el área metropolitana de la ciudad de Monterrey, en México, a quienes se les solicitó contestar de manera voluntaria un cuestionario (instrumento de la encuesta) acerca de sus hábitos y preferencias cinematográficas.

Monterrey cuenta a 2018 con una población de alrededor de 4500000 de habitantes. Con el fin de determinar el tamaño de la muestra para la encuesta, se seleccionó como universo de estudio a los adultos de 18 años o más que asisten regularmente a las salas de cine comercial de la localidad. El tamaño de la muestra se determinó para un mínimo de 400 , siguiendo el criterio de autores como Levin (1979), reconocido estadístico, quien señala que, cuando la población estudiada sobrepasa los 100000 casos, 400 es un número suficientemente representativo. Otros autores como Hernández, Fernández y Baptista (2000, p. 224) mencionan que "las muestras regionales, las que representan algún estado o país o algún municipio o región, están entre rangos de 400 a 700 sujetos". Por su parte, López (1998, p. 50), nos indica que para un universo de 1000000 a 50000000 sujetos un tamaño de muestra suficiente es de 380 sujetos, considerando un nivel de confianza del $95 \%$ y un margen de error de más o menos el $5 \%$.

Considerando estos criterios, el tamaño de muestra que se utilizó para las encuestas que se aplicaron en los años cuyos resultados se mues- 
tran en este artículo (2001-2017) variaba en un rango de 400 a 600 espectadores. El muestreo fue no probabilístico, de sujetos tipo (que hubiesen visto películas mexicanas en las salas de cine en los últimos meses), voluntarios, mayores de 18 años, de ambos sexos, cuidando la paridad de género (mitad hombres y mitad mujeres), seleccionados a discreción para aplicarles el instrumento al salir de las salas de proyección.

\section{Resultados}

\section{Las transformaciones: la producción se descentraliza}

Luego de una época de crisis, y a la vuelta de una generación, el cine mexicano se recupera. A 2017, el Imcine reporta una producción de 176 películas nacionales y 88 estrenos. También reporta 22,4 millones de espectadores de cine mexicano, un indicador más bajo que el de 2016 , que fue de $30,5 \mathrm{mi}$ llones, sin embargo, es el cuarto año con más alta asistencia en las tres últimas décadas detrás de 2016 (30,5 millones), 2013 (30,1 millones) y 2014 (24 millones). Aunque el público que fue a ver películas mexicanas a los cines disminuyó en un $24 \%$ en el último año, de 2010 a 2017 el porcentaje de público que asistió a ver películas mexicanas se ha incrementado casi el doble, del 11,5 al 22,4\% durante este periodo.

Por otra parte, la producción se descentraliza. Si bien la Ciudad de México, capital del país, es la entidad con mayor producción de cine nacional, con el $36 \%$ del total, en 2017 este porcentaje fue siete puntos menos que en 2016 y 14 puntos menos que en 2015, lo que refleja la descentralización de la actividad cinematográfica hacia otros estados y regiones del país.

En 2017 se realizaron filmes en 28 entidades federativas, cinco más que en 2016. Mientras que en 2015 la producción de películas cubría el 68 $\%$ de las entidades, este año abarcó alrededor del $90 \%$ de México.

Jalisco ocupó el segundo lugar con el 7 \% de la producción total a nivel nacional y en tercer lugar quedó Oaxaca con el $5 \%$. Este año Nuevo León (estado de origen de quien esto escribe), que en años anteriores se había ubicado en el tercer lugar, ahora bajó al cuarto con el $3 \%$, junto con Baja California, Guanajuato y Chiapas. 
En resumen, en la última década, se ha visto un crecimiento sostenido en la producción, el número de salas, la asistencia total a los cines y los ingresos en taquilla. El indicador de la asistencia a películas mexicanas ha tenido altas y bajas; sin embargo, puede decirse que en general se ha recuperado.

Como se muestra en la tabla 1 , el cine mexicano se recupera, pero no todo ha sido favorable en esta transformación. La exhibición de películas nacionales en el país desafortunadamente sigue siendo la tarea pendiente, ya que no ha tenido los mismos incentivos que la producción. Si bien en los últimos años se ha incrementado el número de estrenos en pantalla, incluso con apoyo de estímulos federales, las cifras no llegan a la cantidad de estrenos que se tenían antes de los cambios en la legislación que se dieron paralelamente a la entrada del TLCAN, estrenos que eran más proporcionales a la producción, favoreciendo ahora más a las películas extranjeras, básicamente estadounidenses.

Tabla 1. El cine mexicano en números (2010-2017)

\begin{tabular}{|l|c|c|c|c|c|c|c|c|}
\hline & $\mathbf{2 0 1 0}$ & $\mathbf{2 0 1 1}$ & $\mathbf{2 0 1 2}$ & $\mathbf{2 0 1 3}$ & $\mathbf{2 0 1 4}$ & $\mathbf{2 0 1 5}$ & $\mathbf{2 0 1 6}$ & $\mathbf{2 0 1 7}$ \\
\hline $\begin{array}{l}\text { Pantallas } \\
\text { cinematográficas }\end{array}$ & 4905 & 5166 & 5303 & 5547 & 5678 & 5977 & 6225 & 6633 \\
\hline $\begin{array}{l}\text { Películas } \\
\text { extranjeras } \\
\text { estrenadas }\end{array}$ & 313 & 321 & 319 & 364 & 330 & 334 & 317 & 336 \\
\hline $\begin{array}{l}\text { Asistencia total* } \\
\text { Películas } \\
\text { mexicanas } \\
\text { estrenadas }\end{array}$ & 190 & 205 & 228 & 248 & 240 & 286 & 321 & 338 \\
\hline $\begin{array}{l}\text { Asistencia a } \\
\text { ver películas } \\
\text { mexicanas* }\end{array}$ & 11,5 & 13,5 & 10,9 & 30,1 & 24 & 17,5 & 30,5 & 22,4 \\
\hline $\begin{array}{l}\text { Ingresos en } \\
\text { taquill** }\end{array}$ & 9032 & 9755 & 10674 & 11860 & 11237 & 13334 & 14808 & 16142 \\
\hline
\end{tabular}

"Millones de personas

"Millones de pesos

Fuente: Anuario Estadístico de Cine Mexicano (2013, 2014, 2015, 2016, 2017). 
Paradójicamente, en el TLCAN se declara que "el treinta por ciento del tiempo anual en pantalla en cada sala puede ser reservado a las películas producidas por personas mexicanas dentro o fuera del territorio de México" (Anexo I, Lista de México), con lo que resulta que el TLCAN es más benévolo con nuestro cine que su propia legislación. Habrá que ver si en las negociaciones que se están llevando a cabo actualmente se hace algún cambio a lo establecido para el sector. Hasta ahora, tal parece que la industria cultural del cine no está en la agenda de las negociaciones.

\section{El cine mexicano en el contexto iberoamericano: el valor de la mirada latina}

México ocupa actualmente un primer lugar en número de pantallas, asistencia total e ingresos en taquilla con respecto a los países iberoamericanos. En un análisis comparativo con datos a 2015, el número de pantallas en México, que ya sobrepasa las 6600, sitúa al país como el primero en el contexto iberoamericano y el cuarto en el mundo, por detrás de los Estados Unidos, China y la India.

El número de entradas vendidas también ubica al país como el primer país iberoamericano y el cuarto en el mundo en asistencia de espectadores a los cines, aun cuando el precio promedio del boleto en taquilla es uno de los más baratos en Iberoamérica.

Un dato interesante es que en República Dominicana la cuota de espectadores de cine dominicano (casi el $30 \%$ ) fue la más alta entre los países iberoamericanos. Cinco estrenos dominicanos se colocaron en el ranking de más espectadores, de modo que es el país iberoamericano con más producciones exitosas en su propio país en 2015.

El crecimiento en el número de espectadores por año en México solo es superado a nivel mundial por China. En 2014 y 2015, disminuyó en casi el $10 \%$ la asistencia al cine a nivel mundial con respecto a 2013 (tabla 2). 


\section{Tabla 2. Comparativo del mercado cinematográfico entre México, Iberoamérica y Estados Unidos en 2015}

\begin{tabular}{|l|c|c|c|c|c|c|c|c|}
\hline & México & Brasil & Colombia & España & Argentina & Perú & $\begin{array}{c}\text { República } \\
\text { Dominicana }\end{array}$ & $\begin{array}{c}\text { Estados } \\
\text { Unidos }\end{array}$ \\
\hline $\begin{array}{l}\text { Población en } \\
\text { millones }\end{array}$ & 121,7 & 204,2 & 46,7 & 46,4 & 43,4 & 30,4 & 10,4 & 321,3 \\
\hline $\begin{array}{l}\text { Pantallas } \\
\text { cinematográficas }\end{array}$ & 5977 & 3013 & 935 & 3588 & 872 & 553 & 182 & 40547 \\
\hline $\begin{array}{l}\text { Películas } \\
\text { extranjeras }\end{array}$ & 334 & 279 & 265 & 388 & 246 & 239 & 199 & 323 \\
\hline $\begin{array}{l}\text { Asistencia total* } \\
\text { \% cuota mercado } \\
\text { cine nacional }\end{array}$ & 283,3 & 172,9 & 59,1 & 96,1 & 52.1 & 45,6 & 5,3 & 1214,5 \\
\hline $\begin{array}{l}\text { Asistencia a } \\
\text { ver películas } \\
\text { nacionales* }\end{array}$ & 17,5 & 22,5 & 5,8 & 18,6 & 7,5 & 5,6 & 1,6 & 1109,0 \\
\hline $\begin{array}{l}\text { Ingresos en } \\
\text { taquilla* }\end{array}$ & 842,1 & 715,2 & 179,9 & 638,4 & 342,0 & 158,3 & 23,1 & 10201,4 \\
\hline
\end{tabular}

¿Qué condiciones propiciaron que España, Argentina y Brasil tuvieran las cuotas más altas para su cine nacional? España, con una cuota de mercado para su cine nacional del 19,3 \% en 2015 tiene medidas de apoyo para las salas de exhibición que en su programación anual incluyan, en proporción superior al $40 \%$, largometrajes comunitarios e iberoamericanos. Las salas de exhibición están obligadas a programar dentro de cada año natural obras cinematográficas de los Estados miembros de la Unión Europea (UE) de al menos el $25 \%$ del total de las funciones que se hayan programado con obras cinematográficas coproducidas.

Argentina, que tuvo una cuota de mercado para el cine nacional del $14,5 \%$ en 2015, establece que la cantidad mínima de películas argentinas que deben exhibirse obligatoriamente en cada una de las salas cinematográficas del país en cada trimestre calendario será de una película por sala, como mínimo una semana. 
Brasil, con el $13 \%$ de cuota de mercado para su cine nacional, tiene como política cinematográfica que cada año se va estableciendo por decreto el mínimo de días y la cantidad de títulos que deben estrenarse, según estudios técnicos que realiza esta entidad; el mínimo es de 28 días anuales y dos títulos brasileños por sala. También busca fomentar audiencias estableciendo un bono de cultura y subsidio de acceso gratuito.

Tristemente, y de acuerdo con la legislación de cine vigente, México reserva el $10 \%$ del total de pantallas a nivel nacional para las películas mexicanas con una semana como mínimo para su exhibición. Esto propicia que nuestros cineastas mexicanos tengan que emigrar para hacer sus películas en el extranjero, ya que ¿quién va a querer que su película se exhiba solo en 10 de cada 100 pantallas? Tiene que irse a producir a los Estados Unidos para que luego la distribuya una empresa transnacional y su película se exhiba en un gran número de salas de cine en su propio país.

\section{Miradas que valen son poco estudiadas}

En la tradición de la investigación social en México son muy escasos los estudios sobre el cine y, todavía más, de sus públicos. Zavala señala que, "desde sus orígenes hasta nuestros días, la investigación del cine que se ha realizado en el país se ha visto reducida, en su mayor parte, a perspectivas provenientes del periodismo y de la historia, y en mucho menor medida de la sociología, la psicología o la crítica literaria” (2010, p. 87).

En un balance de los trabajos que sobre cine se han realizado en México, Zavala señalaba que de los 30 considerados por él como los más relevantes producidos en los últimos 40 años (de 1968 a 2009), considerando el prestigio académico de sus autores, 25 eran de carácter historiográfico y solo cinco sobre procesos de recepción (lo más cercano a los estudios sobre los públicos).

Entre estos estudios, son reconocidos los históricos de De los Reyes (1983), de compilación de García Riera (1992) y los de reseña y crítica cinematográfica de Ayala Blanco (2003). Más enfocados en los espectadores podemos citar los de García Canclini (1995, 2006, 2007), los de Rosas 
(2006, 2012, 2017) y Cortázar (2013). Pocos se introducen en la exploración en particular de la recepción cinematográfica, pero podemos citar los trabajos de Iglesias (2001), de Torres (2006) y Fernández-Poncela (2016), y sobre los espectadores de cine en su encuentro con las nuevas tecnologías de Gómez (2015) y Bárcenas y Lemus (2015).

En uno de sus trabajos, Rosas señalaba que "el público ha sido el gran ausente en los estudios sobre el cine, tanto de los históricos como de los del campo de la comunicación" (2012, p. 42), y que los balances bibliográficos al respecto coincidían en que en México no se habían realizado sistemáticamente estudios empíricos de los públicos de cine.

Una de las principales dificultades para la realización de estudios sobre los públicos, añade Rosas, ha sido la carencia de fuentes de primera mano. Conscientes de ello, los investigadores se dedican a buscar en periódicos, revistas, documentos y mapas en hemerotecas y oficinas para acceder a esta información.

No es sencillo estudiar, de manera integral, las prácticas de consumo cultural como la cinematográfica. Si bien en las últimas décadas han surgido más estudios históricos, sociales, antropológicos y comunicacionales en torno al cine y sus públicos, estos todavía no alcanzan en cantidad y proyección a los de otras industrias culturales. Como señala Rosas: "Requerimos sumar a las tareas de visibilización de las películas, la investigación sobre las condiciones de transformación de los espectadores contemporáneos. Las condiciones de acceso, la disposición interactiva, pautan otras experiencias cinematográficas que habrá que contemplar desde la producción y las modalidades de oferta" (2017, p. 310). En este sentido, partimos de que las condiciones de producción y exhibición cinematográfica determinan en cierta medida los procesos de consumo y recepción de los espectadores.

Bajo esta premisa, Wasko (2006, pp. 101-102), investigadora de la economía política de la comunicación y la cultura, nos señala que la economía política, como enfoque teórico, representa una perspectiva diferente y distinta del estudio del cine, aunque no haya recibido el reconocimiento debido en el campo de los estudios fílmicos. Un análisis desde la perspectiva 
de la economía política del cine, afirma Wasko, nos ayuda a entender cómo las películas son producidas y distribuidas como mercancía dentro de una estructura industrial capitalista, a describir no solo el estado de esta industria, sino también su desarrollo y relaciones sociales. La economía política del cine incorpora aquellas características que definen la economía política de una industria cultural tan importante como la cinematográfica en un contexto determinado y a través de las cuales podemos describir y explicar su estado actual. Estas características son el cambio social e histórico de la industria, la totalidad social, la base moral y la praxis.

\section{El público detrás de la nueva historia del cine nacional}

Hacen falta estudios empíricos que den cuenta del comportamiento de los públicos de cine desde una perspectiva global/local. Ello nos permitiría profundizar en sus actitudes, opiniones, preferencias y valoraciones hacia los films, con lo que se obtendría información muy valiosa que podría utilizarse por los cineastas, los exhibidores, distribuidores y para elaborar iniciativas con las que promover políticas culturales que apoyen de forma más pertinente a esta industria.

Una mirada local a la asistencia y al consumo de cine en las salas comerciales de una entidad mexicana nos dará una idea de cómo el regreso del público del cine mexicano es el que ha contribuido a que la industria se recupere. La entidad local es Monterrey, estado de Nuevo León, una de las ciudades más importantes del noreste de México.

Las últimas estadísticas del Anuario Estadístico de Cine Mexicano publicados por el Imcine señalan que Nuevo León es una buena plaza para la exhibición cinematográfica. De 2013 a 2016, el estado fue el tercero con mayor número de espectadores de cine mexicano, después del Distrito Federal y Jalisco.

Nuevo León también es el cuarto estado en producción de cine a nivel nacional (hasta el año pasado era el tercero). Actualmente, cuenta con más de 600 salas de cine, es el segundo estado con más salas de cine después de Ciudad de México y el estado con más pantallas en proporción al número de habitantes. 
La variedad de películas que en promedio se exhiben por día en las salas de cine fluctúa entre 29 y 38 , dependiendo de la temporada y si hay algún festival, de las cuales de 4 a 7 son nacionales.

En 2017, disminuyó a 48 el número de películas mexicanas estrenadas en las salas de cine, de 50 que se exhibieron en 2016. Del total de la asistencia a las salas de cine en 2017, el $5 \%$ fue para ver películas mexicanas; en 2016 , fue del $7 \%$. Estos porcentajes, aunque pequeños, son significativos si se contrastan con el número de películas mexicanas que se exhiben en promedio por día.

En las dos décadas pos-TLCAN, en Monterrey, como en el resto del país, la oferta de las películas mexicanas exhibidas en promedio en las salas de cine locales ha sido muy fluctuante y la de películas de origen estadounidense es la que más ha predominado en las pantallas; sin embargo, y a pesar de la escasa oferta de películas mexicanas en las salas comerciales de la ciudad, el público de Monterrey está yendo a verlas.

Como se mencionó, este estudio es parte de una línea de investigación en la que se han venido haciendo análisis empíricos sobre los públicos de las salas de cine comercial en Monterrey y su percepción sobre el cine mexicano exhibido en el periodo de 2001 a 2017. La técnica que se ha venido utilizando es la encuesta y como instrumento un cuestionario de once preguntas, algunas abiertas y otras de opción múltiple, el cual se ha aplicado a espectadores voluntarios de ambos sexos, mayores de edad, a la salida de los cines (el tamaño y proceso de selección de la muestra se describe en el apartado del método de este artículo).

Las preguntas versaron sobre película que asistió a ver a la sala; factor que influyó en la selección de la película (se la recomendaron, consultó la cartelera, por la publicidad que la hicieron, por los actores); si ha visto películas mexicanas en los últimos tres meses (sí, no); si la respuesta es sí, que mencione las últimas tres que haya visto; película mexicana que haya visto últimamente y que le haya gustado más; cómo califica las nuevas películas mexicanas en cuanto producción, actuaciones y temática (muy buenas, 
buenas, regulares, malas, muy malas); en cuanto al contenido en qué medida ha encontrado identificación con los personajes, conocimiento e información, refuerzo de valores, temas de conversación, emociones (mucho, poco, nada); si considera que estas películas tienen semejanza con la realidad (si, no); cuáles películas prefiere ver más (mexicanas, extranjeras); si se exhibieran más películas mexicanas, si asistiría a verlas (sí, no); frecuencia con la que asiste al cine (cada semana, cada quince días, una vez al mes, casi nunca). Además, se tomaron datos sobre sexo, edad, escolaridad, trabajo, estado civil y municipio de residencia.

La tabla 3 muestra que el comportamiento de los patrones de consumo del público de películas mexicanas que asisten a las salas de cine en Monterrey se ha mantenido constante en los años estudiados (salvo en 2009), con una percepción favorable hacia las nuevas películas mexicanas, lo que evidencia que al menos en Monterrey existe un público que valora y consume las producciones mexicanas, aunque su oferta sea escasa.

En 2001, el $56 \%$ contestaron haber asistido a ver películas mexicanas en los últimos tres meses; en 2002, el 73,5\%; en 2006, el $51 \%$; en 2007, el $57 \%$; en 2008, el $65 \%$; en 2009, el $43 \%$; en 2010, el $53 \%$. En 2017, se llevó a cabo una réplica de la encuesta que se había venido aplicando hasta 2010. Los resultados fueron significativos.

\section{Tabla 3. Espectadores que vieron películas mexicanas en las salas de cine comercial de Monterrey en los últimos tres meses en 2001, 2002, 2006, 2007, 2008, 2009, 2010, 2017}

\begin{tabular}{|l|c|c|c|c|c|c|c|c|}
\hline $\begin{array}{c}\text { Vieron } \\
\text { películas } \\
\text { mexicanas }\end{array}$ & $\mathbf{2 0 0 1}(\%)$ & $\mathbf{2 0 0 2}(\%)$ & $\mathbf{2 0 0 6}(\%)$ & $\mathbf{2 0 0 7}(\%)$ & $\mathbf{2 0 0 8}(\%)$ & $\mathbf{2 0 0 9}(\%)$ & $\mathbf{2 0 1 0}(\%)$ & $\mathbf{2 0 1 7}(\%)$ \\
\hline Sí & 56 & 73,5 & 51 & 57 & 65 & 43 & 53 & 55 \\
\hline No & 44 & 26,5 & 49 & 43 & 35 & 57 & 47 & 45 \\
\hline No contestaron & 0 & 0 & 0 & 0 & 0 & 0 & 0 & 0 \\
\hline Total & 100 & 100 & 100 & 100 & 100 & 100 & 100 & 100 \\
\hline
\end{tabular}

Fuente: elaboración propia. 
Cabe señalar que en 2002, cuando se registró un 73,5 \% que había asistido a ver películas mexicanas en los últimos tres meses, fue el estreno de la película El crimen del padre Amaro, protagonizada por Gael García, la cual fue vista, según contestaron, hasta tres veces por algunos de los espectadores encuestados. En 2008, se estrenó Rudo y Cursi, protagonizada por Gael García y Diego Luna, película mexicana que también atrajo a un buen número de asistentes. Por otra parte, si bien en 2009 el porcentaje de asistentes que vieron películas mexicanas disminuyó al $43 \%$, en 2010, se volvió a incrementar de nuevo a un $53 \%$, año en que también se incrementó el número de películas mexicanas exhibidas en las salas de cine con motivo de los festejos del Centenario de la Revolución Mexicana y el Bicentenario de la Independencia, lo que llevó al interrogante de que, ¿̇i se exhibieran más películas mexicanas en los cines, la gente iría a verlas?

Esta pregunta se agregó al cuestionario que se aplicó a 480 espectadores en mayo de 2011 y a 450 en noviembre de 2017, cuyos resultados se muestran en la tabla 4.

\section{Tabla 4. Si se exhibieran más películas mexicanas, ¿vendría a verlas?}

Encuesta a espectadores en las salas de cine en el periodo de 2011 a 2017

\begin{tabular}{|l|c|c|}
\hline \multicolumn{1}{|c|}{ Respuesta } & $\mathbf{2 0 1 1}(\%)$ & $\mathbf{2 0 1 7}(\%)$ \\
\hline Sí & 72 & 80 \\
\hline No & 27 & 20 \\
\hline No contestó & 1 & 0 \\
\hline Total & 100 & 100 \\
\hline
\end{tabular}

Fuente: elaboración propia.

En la última encuesta de 2017, también se les preguntó a los sujetos que de qué manera acostumbraban a ver más las películas: el $48 \%$ contestaron que en las salas de cine, el $26 \%$ que en la TV de paga, el $16 \%$ que las baja de internet, el $5 \%$ que las ve en TV abierta, el $3 \%$ que rentadas y el 2 $\%$ que compradas. Si bien las nuevas plataformas de internet son atractivas para que los jóvenes vean las películas, todavía casi la mitad prefiere verlas en 
las salas de cine. De los 450 encuestados, el $84 \%$ tenían un rango de edad de entre los 18 a los 35 años. De lo anterior se desprende que las salas de cine siguen siendo todavía una opción de acceso preferente para los cinéfilos.

Un dato interesante, y que reafirma que Monterrey es una buena plaza para el cine mexicano, es que, a pesar de que Nuevo León fue uno de los estados con menor cuota de mercado para el cine nacional en 2017, el estado ocupó el tercer lugar en asistencia a ver películas mexicanas a nivel nacional. Es decir, que, aunque se exhibieron menos películas mexicanas en las salas de cine que en el resto de los estados del país, el público fue a verlas.

El perfil de este público no ha cambiado en el transcurso del periodo que abarca nuestro estudio. Desde 2001 se detectó que el perfil de los asistentes a las salas de cine comercial sigue siendo en su mayor parte de jóvenes de entre los 18 a los 25 años ( $64 \%)$, con estudios profesionales, solteros y con trabajo (el $60 \%$, en promedio, han contestado contar con trabajo en el momento de responder el cuestionario), de lo que se infiere que el público que asiste a las salas de cine comercial a ver películas mexicanas se está convirtiendo en una "élite", dejando a gran parte de la población (clases populares) fuera del disfrute de este patrimonio cultural.

En un país donde, de acuerdo con las métricas de la Endutih 2017 (Encuesta Nacional de Uso de las Tecnologías de Información en los Hogares), 17,4 millones de hogares en el país (50,9\% del total) disponen de una conexión a internet y la contabilidad de usuarios de internet asciende a 71,3 millones, esto es, 63,9 de cada 100 mexicanos de 6 años o más, ver películas en las salas de cine comercial puede seguir siendo una opción viable de disfrute para quienes no tienen acceso a las tecnologías de la información y de la comunicación (TIC), considerando que el costo del boleto puede ser accesible dependiendo de la ubicación del complejo cinematográfico. En Monterrey, varía de MXN 35 a 150.

\section{Conclusiones}

Como se expuso en este trabajo, luego de una etapa de gran crisis, el cine mexicano se recupera mostrando incrementos en la producción, en el 
número de salas de cine, en los indicadores de asistencia y taquilla, en una transformación en su nueva etapa y en la vuelta del público que tiene un gran papel en su recuperación. Sin embargo, seguimos viendo una continuidad en la escasa exhibición en salas y en la inercia de nuestros legisladores para no trabajar en una reforma legislativa del sector que propicie las condiciones estructurales para que el cine mexicano tenga un fomento, promoción y difusión sostenidos.

Por otra parte, si bien la industria cinematográfica mexicana ocupa un lugar preponderante con respecto a otros países iberoamericanos, se encuentra rezagada en cuanto a la cuota de pantalla que destina al cine nacional. También son pocos los estudios comparativos sobre los públicos entre países iberoamericanos; los que realizan entidades internacionales como la Entidad de Gestión de Derechos de los Productores Audiovisuales (Egeda, 2016) son valiosos, pero hacen falta más estudios empíricos que contrasten lo global con lo local, conocer más acerca de los públicos de nuestros países para ver de qué manera podemos desarrollar iniciativas que coadyuven a fomentar la formación de públicos para nuestras cinematografías.

Tenemos que aprovechar que los países iberoamericanos compartimos una lengua en común, cultura, historia e idiosincrasias, pero también el mismo control que las distribuidoras transnacionales ejercen sobre la exhibición de nuestros films.

En resumen, el cine mexicano está viviendo un cambio social e histórico con su recuperación nacional y proyección internacional gracias a los éxitos que en el extranjero están obteniendo algunos de sus cineastas; la totalidad social, si bien somos testigo de ello, no todos tenemos una participación justa y equitativa, los cineastas en la producción y exhibición, y los espectadores en su consumo y disfrute; en su base moral, están esta inequidad y la necesidad de invocar la voluntad política de nuestros legisladores para trabajar en una reforma que permita que nuestros cineastas no tengan que emigrar para ser reconocidos y que su producción beneficie al país, y que más mexicanos disfruten de estos bienes culturales para que el producto de la praxis cinematográfica sea más inclusivo. 
¿Qué proponemos para que esta industria siga con este crecimiento sostenido?

Es imperante una política cultural congruente y consistente de parte del Gobierno federal para el cine mexicano que fomente su desarrollo, promoción y exhibición.

Aprovechar al menos la prerrogativa que nos concede el TLCAN actual del $30 \%$ de pantalla para las películas mexicanas, mientras sigue vigente, reformando nuestra legislación de cine.

Recuperar el cine como un emprendimiento tanto comercial como cultural, con más y mayores apoyos federales para la producción y exhibición.

Crear una cuota para el desarrollo cinematográfico en la que distribuidores y exhibidores contribuyan con un porcentaje de los ingresos obtenidos por la venta o negociación de derechos de ingreso a la exhibición o comercialización cinematográficas en salas de cine.

Formar públicos/espectadores críticos desde el nivel básico de educación.

Socializar el acceso al cine mediante promociones como bonos para trabajadores y entradas gratuitas para los sectores marginales (como se hace en Brasil).

Recuperar el cine como un espacio social de esparcimiento, formación de identidad nacional, respeto por la diversidad y promoción cultural.

\section{Colofón}

Durante el último lustro, tres cineastas mexicanos han acaparado los Premios Óscar a mejores películas produciendo un cine transnacional y dejando la mayor parte de las ganancias en los Estados Unidos. Primero fue Alfonso Cuarón (Gravity, 2014); luego Alejandro González Iñárritu (Birdman, 2015; The Revenant, 2016); y ahora Guillermo del Toro (The Shape of Water, 2018). Ninguno de ellos siguió un camino convencional por el cine 
nacional, sino que los tres tuvieron que emigrar para que su trabajo fuera reconocido; las temáticas de sus películas no tienen que ver con nuestra cultura mexicana. El triunfo, pues, ha sido de los cineastas, no del cine mexicano.

También están los triunfos de un cine más comercial, pero atractivo para el público, de Eugenio Derbez, No se aceptan devoluciones (2013), Cómo ser un Latin lover (2016) y Hombre al agua! (2018). La primera, producida en México, en la que produce y actúa Derbez; las dos últimas fueron realizadas en los Estados Unidos y en ellas actúa Derbez. Estas películas están dirigidas a un público hispano que se globaliza.

El público no nace como tal, sino que el público se hace, se forma, se educa. Terminamos este trabajo con nuestra hipótesis milenaria que sigue abierta a la investigación: si se estimulara más la producción y exhibición de películas nacionales, nuestros cineastas harían más películas en el país y tendríamos más espectadores que las verían. Y sus miradas valen.

\section{Referencias}

Anuario Estadístico de Cine Mexicano 2013. Recuperado de https://www. imcine.gob.mx/cine-mexicano/publicaciones/anuario-estadistico

Anuario Estadístico de Cine Mexicano 2014. Recuperado de https://www. imcine.gob.mx/cine-mexicano/publicaciones/anuario-estadistico

Anuario Estadístico de Cine Mexicano 2015. Recuperado de https://www. imcine.gob.mx/cine-mexicano/publicaciones/anuario-estadistico

Anuario Estadístico de Cine Mexicano 2016. Recuperado de https://www. imcine.gob.mx/cine-mexicano/publicaciones/anuario-estadistico

Anuario Estadístico de Cine Mexicano 2017. Recuperado de https://www. imcine.gob.mx/cine-mexicano/publicaciones/anuario-estadistico

Ayala Blanco, J. (2003). El cine actual: desafío y pasión. Ciudad de México, México: Océano. 
Bárcenas Curtis, C. y Lemus Pool, M. C. (2015). El espectador cinematográfico en un contexto digital. Cambios y continuidades en las prácticas y hábitos. Versión: Estudios de Comunicación y Política, 36, 23-41. Recuperado de http://version.xoc.uam.mx/tabla_contenido.php?id_fasciculo $=710$

Cortázar Rodríguez, F. J. (2013). Cines y públicos en Guadalajara, 19922009. El ojo que piensa, Revista de cine iberoamericano, 4(7), 1-37. Recuperado de http://www.elojoquepiensa.cucsh.udg.mx/index. php/elojoquepiensa/article/view/140

De los Reyes, A. (1983). Cine y sociedad en México 1896-1930. Vol. 1: Vivir de sueños (1896-1920). Ciudad de México, México: Universidad Nacional Autónoma de México.

Entidad de Gestión de Derechos de los Productores Audiovisuales. (2016). Panorama audiovisual iberoamericano 2016. Madrid, España: Autor. Recuperado de http://www.egeda.com/documentos/Panorama_Audiovisual_Iberoamericano_2016.pdf

Fernández-Poncela, A. M. (2016). México, cine, emociones y...| México, Cinema, Emotions and ... Razón y Palabra, 93, 531-599. Recuperado de http://www.revistarazonypalabra.org/index.php/ryp/ article/view/34

García Canclini, N. (1995). Consumidores y ciudadanos. Barcelona, España: Grijalbo.

García Canclini, N. (2006). La industria cinematográfica en México y en el extranjero. En N. García Canclini, A. Rosas Mantecón y E. Sánchez Ruiz (Coords.), Situación actual y perspectivas de la industria cinematográfica en México y en el extranjero (pp. 293-315). Guadalajara, México: Universidad de Guadalajara.

García Canclini, N. (2007). Lectores, espectadores e internautas. Barcelona, España: Gedisa. 
García Riera, E. (1992). Historia documental del cine mexicano. Número 2, 1938-1942. Guadalajara, México: CONACULTA/IMCINE/Universidad de Guadalajara

Gómez, H. (2015). Hacer vida en las pantallas. De Fans en tiempos del cine después del cine: post-cine, post-culturas, post-fandoms. Versión: Estudios de Comunicación y Política, 36, 42-64. Recuperado de http://version.xoc.uam.mx/tabla_contenido.php?id_fasciculo $=710$

Hernández Sampieri, R., Fernández Collado, C.y Baptista Lucio, P. (2000). Metodología de la investigación. Ciudad de México, México: McGraw-Hill.

Iglesias, N. (2001). Al danzón que me toquen salgo: subjetividad, cine y recepción por género. En Y. Mercader Martínez y P. Luna (Comps.), Cruzando fronteras cinematográficas. Ciudad de México, México: Universidad Autónoma Metropolitana, Unidad Xochimilco.

Ley Federal de Cinematografía, nueva ley publicada en el Diario Oficial de la Federación el 29 de diciembre de 1992.

Levin, J. (1979). Fundamentos de la estadística en la investigación social. Ciudad de México, México: Harla.

López, H. (1998). La metodología de encuesta. En L. J. Galindo Cáceres (Coord.), Técnicas de investigación en sociedad, cultura y comunicación (pp. 33-73).Ciudad de México, México: Addison Wesley Longman.

Organización de los Estados Americanos (s. f.). Tratado de Libre Comercio de América del Norte. Recuperado de http://www.sice.oas.org/trade/nafta_s/ANEXO1b.asp

Rosas Mantecón, A. (2006). Las batallas por la diversidad: exhibición y públicos de cine en México. En N. García Canclini, A. Rosas Mantecón y E. Sánchez Ruiz (Coords.), Situación actual y perspectivas de 
la industria cinematográfica en México y en el extranjero (pp. 263292). Guadalajara, México: Universidad de Guadalajara.

Rosas Mantecón, A. (2012). Públicos de cine en México. Alteridades, 22(44), 41-58. Recuperado de https://alteridades.izt.uam.mx/ index.php/Alte/article/view/87

Rosas Mantecón, A. (2017). Ir al cine: antropología de los públicos, la ciudad $y$ las pantallas. Barcelona, España: Gedisa.

Torres San Martín, P. (2006). La memoria del cine como extensión de la memoria cultural. Revista Culturales, 2(4), 50-79. Recuperado de http://culturales.uabc.mx/index.php/Culturales/article/view/30

Wasko, J. (2006). La Economía Política del cine. Cuadernos de Información y Comunicación, 11, 95-110. Recuperado de http://revistas.ucm. es/index.php/CIYC/article/view/CIYC0606110095A

Zavala, L. (2010). Los estudios sobre cine en México: un terreno en construcción. En M. Moguillansky, A. Molfetta y M. A. Santaguada (Coords.), Teorías y prácticas audiovisuales: Actas del Primer Congreso Internacional de la Asociación Argentina de Estudios de Cine y Audiovisual (pp. 49-77), Buenos Aires, Argentina: Teseo. 